\title{
Development and validation of sources of entrepreneurial self-efficacy and outcome expectations: A social cognitive career theory perspective
}

\author{
Adeola Samuel Adebusuyi ${ }^{\text {a, }}$, Olubusayo Foluso Adebusuyi ${ }^{\mathrm{b}}$, Oluwaseun Kolade ${ }^{\mathrm{c}}$ \\ a Department of Psychology, Nigeria Police Academy, Wudil, Kano, Nigeria \\ b Department of Science and Technology Education, Olabisi Onabanjo University, Ago-Iwoye, Nigeria \\ ${ }^{\mathrm{c}}$ Department of Management \& Entrepreneurship, Leicester Castle Business School, De Montfort University, Leicester, LE1 9BH, UK
}

\section{A R T I C L E I N F O}

\section{Keywords:}

Sources of self-efficacy and outcome expectations

Social cognitive career theory

Personal mastery

Verbal persuasion

Vicarious learning

Positive emotion

Negative emotion

\begin{abstract}
A B S T R A C T
The purpose of this study is to develop and validate the sub-dimensions of the learning experiences sources of self-efficacy and outcome expectations of social cognitive career theory (SCCT) in the domain of entrepreneurship. The validation process was done in three phases. The first phase was the item generation and expert reviews of the items. In the second phase ( $\mathrm{N}=335$ students), we subjected the scale to exploratory factor analysis (EFA) and discovered 5-theory consistent factors. In the third phase $(\mathrm{N}=376)$, we collected another independent sample to further validate the scale, using confirmatory factor analysis (CFA) and a whole spectrum of validity approaches. Overall, the results suggested that the scale is psychometrically sound and supported the theory consistent five-factor structure, with adequate reliability estimates. Our proposed instrument addresses the limitations of previous intention-based models by incorporating other theory that accounts for the achievement of entrepreneurial intention and behaviour outcomes. Finally, we highlight pedagogical, policy and practical implications.
\end{abstract}

\section{Introduction}

This paper proposes a new measuring instrument that can more adequately capture the sources of self-efficacy and outcome expectations as posited by social cognitive career theory (SCCT) by Lent, Brown, and Hackett (1994) within the context of entrepreneurship. The present study is set against the backdrop of critique of intention-based theories and their limitations and the alternative framework offered by SCCT. SCCT has a more robust ability to predict many entrepreneurial outcomes, especially new venture creation, better than previous psychological theories. Therefore, scholars (Carsrud, Brännback, Elfving, \& Brandt, 2009; Liguori, Bendickson, \& McDowell, 2018; Liñán \& Fayolle, 2015) have called for the application of SCCT in an entrepreneurial context. Several researchers (Lanero, Vázquez, \& Aza, 2016; Liguori, Winkler, Vanevenhoven, Winkel, \& James, 2019; Meoli, Fini, Sobrero, \& Wiklund, 2020; Vanevenhoven \& Liguori, 2013) have begun to respond to this call. However, most of their works have concentrated on the proximal aspects of the theory, leaving the distal parts of the theory unexplored.

One crucial variable in the distal parts is learning experiences. Learning experiences are variables conceived by Bandura (1986;

\footnotetext{
* Corresponding author.

E-mail addresses: adedejiadebusuyi@gmail.com, adedejiadebusuyi@polac.edu.ng (A.S. Adebusuyi), adebusuyi.olubusayo@oouagoiwoye.edu.ng (O.F. Adebusuyi), seun.kolade@dmu.ac.uk (O. Kolade).
} 
1997) to serve as the primary sources of self-efficacy. Lent et al. (1994) further posited that these variables could serve more function as a connecting bridge between the distal and proximal parts of SCCT. It, therefore, seems reasonable to argue that the entrepreneurial application of the distal aspects of the theory is hampered by the lack of a validated scale to measure entrepreneurial learning experiences (ELE). Some individuals may argue that most of the research on the antecedents of entrepreneurial self-efficacy (ESE) has been based on the learning experiences, according to Newman, Obschonka, Schwarz, Cohen, and Nielsen (2019). Nevertheless, as will be discussed in the latter parts of this study, we argue that prior works in entrepreneurship did not conceptualize and measure learning experiences as defined by Bandura (1986; 1997). Therefore, those related constructs could not be applied within the SCCT framework. There are few exceptions (such as Erikson, 1999; Farashah, 2015; Mauer, Eckerle, \& Brettel, 2013) that tried to measure ELE as defined by Bandura. However, they did not validate the research instruments. Besides, Farashah (2015) scale may be used only for adults who are practicing entrepreneurs. Furthermore, following Moberg's (2013) argument that entrepreneurship should expand beyond the business school and be taught to all students, regardless of their discipline, we argue that there is a need for a validated ELE scale that can be used among students who have little or no entrepreneurial experience.

Therefore, this study fills this gap by developing and validating an ELE scale for students with little entrepreneurial experience. Filling the gap in knowledge in this regard should open up the distal aspect of SCCT for entrepreneurial research and provide more depth of knowledge on several entrepreneurial outcomes.

\subsection{Outline of the study}

The subsequent section of this paper contains a general review of the SCCT. Next, we discuss why SCCT is a crucial and better theory than the extensively used intention-based theory that permeates entrepreneurship literature. In the next section, we discuss the learning experiences aspect of the theory and why their application is faulty in an entrepreneurial context. The next section is the methodology. It comprises three phases. In the first phase, we discussed how the items were generated to capture ELE as Bandura (1997) and Lent et al. (1994) posited. Also, we discuss the initial stage of face validity done by a panel of expert reviewers. In the second phase, we discussed how the items were validated through exploratory factor analysis (EFA). In the third phase, we discussed further validation processes comprising construct validity, confirmatory factor analysis (CFA), convergent validity and discriminant validity. Furthermore, in this phase, we conducted a composite reliability test, as scholars argue that it is better than the typical Cronbach's alpha (Fornell \& Larcker, 1981). The next section is the results section. Here, we present the EFA results in the second phase. This is followed by the construct validity results, CFA, convergent and discriminant validity, and reliability. Finally, we had the discussion section, the implications of the research and its limitations.

\section{Literature review}

\subsection{Social cognitive career theory: an overview}

With roots in vocational psychology, SCCT aims to provide a unifying framework for explaining experiential and cognitive processes that account for an individual's career choices. It emphasizes the roles of personal agency and human capacity. The theory brings together five inter-connected models: interest development, choice-making, performance and persistence in educational and vocational domains, satisfaction and well-being in educational and vocational contexts, and career self-management (Lent \& Brown, 2019). In effect, SCCT provides an integrated framework for many theories relating to educational and career interest, choice, and behaviour (Lent \& Brown, 2019; Schaub \& Tokar, 2005; Tokar, Thompson, Plaufcan, \& Williams, 2007). It analyzes the content of people's career development (i.e., what career preference you wish for). The theory triadic-reciprocal model of causality accounts for the interactions between personal attributes, external environmental factors, and overt behaviours.

The theory can be divided into two broad parts - the proximal and distal portions. The proximal portions comprise self-efficacy, outcome expectations, goals, etc. Self-efficacy refers to people's perception of their capability to organize and implement actions required to achieve designated outcomes and performance (Bandura, 1986). While self-efficacy focuses on an individual's response capabilities, outcome expectations refer to the imagined consequences of performing particular behaviours. Outcome expectations can be physical, social, or self-evaluative. A goal is defined as the determination or ability of an individual to engage in a particular activity or behaviour in order to effect a particular future outcome. It highlights the agency of individuals to shape, organize, and guide their behaviours, even in the absence of external reinforcement, towards a future outcome. The distal portions include person inputs (e.g., ethnicity/race, gender), contextual affordances (e.g., socioeconomic status [SES]), and learning experiences (comprising personal mastery, vicarious learning, verbal persuasion, and emotion). Thus, Lent et al. (1994) present three distinct but interlocking models to highlight the socio-cognitive mechanisms that influence career and academic development from interest development to choice and performance.

\subsection{Social cognitive career theory and entrepreneurial process}

Personal agency is at the heart of the entrepreneurial process, focusing on the means and actions through which individuals discover, evaluate and exploit opportunities for value creation and value capture. Intention models, such as Ajzen's theory of planned behaviour (Ajzen, 1991), have made significant contributions in explaining some situational and cognitive factors associated with entrepreneurship. However, they have failed to adequately grapple with the complexity and non-linearity of the entrepreneurial process (Liguori et al., 2018). While previous psychological models put intention at the core of the entrepreneurial process, SCCT 
provides a more comprehensive framework that enables scholars to move beyond this limiting and limited intention-based perspective. In other words, the SCCT model recognizes that, while intention is an important starting point in the journey to new venture creation, intention alone is not sufficient (Meoli et al., 2020).

For example, current empirical attention is on the intention-behaviour link or implementation intention. Some empirical (e.g. Neneh, 2019; Pham, Jones, Dobson, Liñán, \& Viala, 2021) works are beginning to surface in this regard. Furthermore, other areas such as entrepreneurial success are calling for more research attention (Staniewski \& Awruk, 2019). SCCT provides an excellent framework to investigate all these emerging areas from both the distal and proximal variables. In summary, SCCT provides a framework to analyze transition to entrepreneurship not as a final destination but as a process embedded in a career path, and where a wider range of antecedents and outcomes come into play (Pérez-López, González-López, \& Rodríguez-Ariza, 2019). Against this backdrop, we highlight four key constructs that elucidate the entrepreneurial learning experiences (ELE) within the social cognitive career theory model.

\subsection{Entrepreneurial learning experiences (ELE)}

Given the primary purpose of this study, we will discuss how learning experiences have been applied in the entrepreneurial context and the limitations of such applications that further warranted this study. Within the SCCT model, learning experiences occupy a spot where they can function as either an outcome, predictor, or mediating variable. We discuss its sub-dimensions within the context of entrepreneurship below.

2.3.1 Entrepreneurial Personal Mastery (EPM). This has to do with past performances influencing future performances in a similar domain. A person who has had success in the past as an entrepreneur has more confidence to do it again. Although researchers (e.g., Bike, 2013) have commented on the moderating impact of cognitive assessment of performance, generally speaking, successful performance in a particular area has been found to increase self-efficacy and outcome expectations in that area (Lent, Ireland, Penn, Morris, \& Sappington, 2017). Entrepreneurship research has studied this variable in the form of prior entrepreneurial experience (e.g., Lee, Hallak, \& Sardeshmukh, 2016; Zhao, Seibert, \& Hills, 2005). However, previous experience is not EPM. It only provides an opportunity to have an EPM. That is, two individuals can have similar EPM, yet one judged himself a failure, while the other judged himself a success. Thus, EPM is a subjective assessment of entrepreneurial performance.

2.3.2 Entrepreneurial vicarious learning (EVL). This has to do with observing models (Lent et al., 2017). The mere act of observing others should produce a subjective perception of being able to do what they do to get what they have acquired. This aspect of learning experiences has been explored considerably in entrepreneurship research. Having family, friends, acquaintances, etc., engage in entrepreneurial activities has been found to predict ESE (BarNir, Watson, \& Hutchins, 2011; Farashah, 2015; Vanevenhoven \& Liguori, 2013) and entrepreneurial intention (Abbasianchavari \& Moritz, 2021; Nowiński \& Haddoud, 2019).

However, we argue that exposure to entrepreneurial models or coming from a family of entrepreneurs does not automatically mean having an entrepreneurial role model. Indeed, there are lots of career models an individual will be exposed to - particularly, a high SES individual (Adebusuyi, Kolawole, Abu, Adebusuyi, \& Ajulo, 2021; Duffy Blustein, Diemer, \& Autin, 2016). Therefore, the decision to pick entrepreneurial models depends on the individual's psychological characteristics and the entrepreneurs they have access to. For example, research has shown that personality traits like risk-taking propensity and the need for achievement separate those who are entrepreneurially inclined from those who are not (Sun, Ni, Teh, \& Lo, 2020). Similarly, Nowiński and Haddoud (2019) reported that individuals are only inspired by successful entrepreneurs. In summary, having an entrepreneurial role model is beyond being exposed to such models. Entrepreneurs become role models if the observer values and desires the benefits of being an entrepreneur (i.e. entrepreneurially inclined) and the type of entrepreneurs they are exposed to.

2.3.3 Entrepreneurial verbal persuasion (EVP). This has to do with the words of encouragement from people you love and whose opinions you respect (Lent et al., 2017). It is a morale-boosting variable that makes the actor persevere in the face of challenges and/or setbacks. Encouraging a person to persevere with a given task implies that the person has been seen making attempts to do the task. In this instance, the actor has probably been seen to exhibit entrepreneurial behaviours in the past. From this perspective, one can argue that entrepreneurial EVP is the opposite of EPM. The former is about past failure, whereas the latter is about past success.

There is another variable that is similar to EVP and common in the entrepreneurial literature - it is the subjective norm. It is defined as social pressure by significant others to carry out entrepreneurial activities (Liñán \& Chen, 2009). The former is about others asking you to continue in what you are doing, whereas the latter is others asking you to start what they think is suitable for you. In other words, the subjective norm is a push entrepreneurial motivation, whereas EVP is a pull entrepreneurial motivation.

Compared to other ELE subscales, EVP has received the least attention in the entrepreneurial literature (Mauer et al., 2013). Besides, the few studies that have investigated it did not measure it accurately. For instance, Erikson (1999) and Mauer et al.'s (2013) measured entrepreneurial EVP in a way analogous to subjective norms. Farashah (2015) measurement tool reads: "You often see stories in the public media about successful new businesses and entrepreneurs." This item seems to be a tool to measure entrepreneurial EVL instead of EVP. Also, none of the past measures of EVP reported psychometric properties of reliability and validity.

2.3.4 Emotional arousal. Emotion in entrepreneurship studies has been acknowledged by many researchers (Fodor \& Pintea, 2017; Cardon, Foo, Shepherd, \& Wiklund, 2012; Cardon, Gregoire, Stevens, \& Patel, 2013). They showed that emotion is useful in the exploration and exploitation of entrepreneurial opportunities, the ability to raise investment funds, hire and motivate workers, etc. Lent et al. (2017) further theorized that emotional arousal in the SCCT model could be broken down into distinct parts of positive emotion (PE) and negative emotion (NE). Most of the emotion measures in the literature are useful for practising entrepreneurs. Also, past research that has investigated ELE did not either include emotional arousal (e.g., Erikson, 1999), correctly measure it (e.g., Mauer et al., 2013) or further break it down into entrepreneurial positive (EPE) and negative emotion (ENE), as was posited by Lent et al. 
(2017).

In summary, there is a dire need for a psychometrically sound scale to measure ELE. Filling the gap in knowledge in this regard should open up the distal aspect of SCCT for other entrepreneurial researchers.

\section{Methodology}

\subsection{Phase 1: item generation}

Based on a closer study of the sources of self-efficacy by Bandura (1997), we developed 40 items to measure EPM (12 items), EVP (14 items), and EVL (14 items). Items were written in a first-person statement, and some of them were negatively worded. For EPM, however, two items were adapted from early commercialization behaviour, a subscale of early entrepreneurial competence scale by Obschonka, Silbereisen, Schmitt-Rodermund, and Stuetzer (2011).

The items and a brief explanation of each ELE subscale as posited by Bandura (1997) were sent to a panel of reviewers who have at least a master's degree in any social sciences fields (e.g. psychology, sociology, economics, and business administration) and are lecturers. We mixed the items up such that items designed for a particular factor were not serially arranged. So, the reviewers' job was to read each item and, based on the definition of each subscale they had read, identify where each item should belong. Also, they should check each item for relevance, confusing sentences, and suggest any addition or subtraction they feel is necessary. Three persons responded and became the three-man panel that reviewed the items. Two were from the psychology department, and the last person was from business administration. The two in psychology have 10 and 14 years of lecturing experience, and the last person has 15 years of lecturing experience. The three-man panel identified each item, and where their identification did not agree, the authors used their discretion to determine where the item should be. Furthermore, items they felt were ambiguous were either reworded or deleted. This process reduced the number of items to 30. These items are presented in the appendix of this paper. For emotional arousal, however, we did not send the items out to be reviewed since we were only adapting an existing scale.

\subsection{Phase 2: exploratory factor analysis}

\subsubsection{Sampling technique}

For phase 2, we sampled the three major ethnic groups in Nigeria (Yoruba, Igbo, and Hausa) to provide generalizability for the scale. We collected samples from Obafemi Awolowo University, Ile-Ife, (a university in southwestern Nigeria) that is chiefly populated by Yoruba students. We also collected data at the University of Nigeria, Nsukka (a university in southeastern Nigeria), whose student population is predominately Igbo. For the Hausa participants, we collected data from Kano State Polytechnic (a higher institution of learning in northern Nigeria).

\subsubsection{Participants}

The participants in this phase were 335 students. Forty-five (13.4\%) were postgraduate students, while 290 (86.57\%) were undergraduate students. There were 181 (54\%) males, $152(45.4 \%)$ females, and two $(0.6 \%)$ did not indicate their sex. Their ages ranged from 18 to $48(\mathrm{M}=25.26, \mathrm{SD}=4.67)$ years. On ethnicity, Yoruba were $78(23.3 \%)$, Igbo were $134(40 \%)$, and Hausa were 123 (36.7\%). On religion, 195 (58.2\%) were Christians, 137 (40.9\%) were Muslims, and $3(0.9 \%)$ did not indicate their religion. The respondents were from faculties and departments of the tertiary institutions used. Out of the 335 respondents, 56 (16.72\%) had 1 to 3 item responses missing.

\subsubsection{Procedure}

We presented the 30 items retained in phase 1 . Also, we adapted the 20-item Positive and Negative Affect Schedule (PANAS) by Watson, Clark, and Tellegen (1988) to fit the entrepreneurial context in order to measure entrepreneurial PE and NE. However, the whole 20 items were not adapted. The item "guilty" was removed since it could not be felt in an entrepreneurial context.

On the questionnaire, the first part comprised demographic information such as sex, department, state of origin, religion, and age. The instruction reads: "On a 6-point scale, from (1) strongly disagree to (6) strongly agree, how would you rank yourself in the following:" after that followed the 30 items. For emotional arousal, the instruction reads: "When you hear, think, or others talk about entrepreneurship in the past, to what extent have you felt ...." The response format was on a scale of 1 (very slightly not at all true) to 5 (extremely true of me). Furthermore, we added three additional items that are not related to the study to exclude mindless respondents. An example of this is "I sleep less than 1 hour per night".

\subsubsection{Data screening}

Since the data collected were in a paper and pencil format, we manually entered the data into SPSS version 21 . We checked the data for anomalies such as non-normality, unengaged responses, extreme values, missing data, skewness and kurtosis. We checked for nonnormality using histograms and boxplots. Extreme values occurred due to the manual approach of data entry. We anticipated this problem; therefore, we uniquely labelled each questionnaire so that we could go back to it when we encountered an extreme value. Unengaged responses were deleted. Skewness and kurtosis were also within an acceptable range of -2 to +2 (Weston \& Gore, 2006). Finally, as Tabachnick and Fidell (2013) recommended, we used full information maximum likelihood (FIML) to generate data for the missing values in the dataset. Statistical scholars (e.g. Singer \& Willett, 2003; Tabachnick \& Fidell, 2013) argue that it is the best approach to handle missing data. We carried out the same process of data screening for the other study carried out in this paper. 


\subsection{Phase 3: validity analysis}

In phase 3, we present the scale in another independent sample. The purpose of this phase is to conduct further validation by estimating construct validity, CFA, convergent and discriminant validity, and composite reliability.

\subsubsection{Construct validity}

According to DeVellis (2017), the requirement for construct validity is satisfied if the new scale relates to other scales in a theoretically predetermined way. In the theoretical reasoning of SCCT, ELE subscales should correlate positively with ESE and entrepreneurial outcome expectations (EOE). The only exception is ENE, in which case we expect it to relate negatively to ESE and EOE. Conversely, we included the neuroticism personality subscale, defined as a trait-based negative emotion. We expect it to negatively connect to other ELE subscales but positively relate to the ENE subscale. Furthermore, we subject the EFA result in phase 3 to CFA to cross-check the scale's factor structure using this different sample.

\subsubsection{Confirmatory factor analysis}

We further validate the scale's factor structure by conducting CFA and checking the factor loadings and the fitness statistics of the hypothesized model, as recommended by Iacobucci (2010) and Worthington and Whittaker (2006). In addition, following the examples of Lent, Lopez, Brown, and Gore (1996) and Lent et al. (2017), we considered alternative models of CFA. First, previous scale development procedures in the career literature have found personal mastery and verbal persuasion to covary substantially, and they tried to test a model where the two forms one factor, alongside other factors. Similarly, we did a 4-factor model, where EPM and EVP formed one factor. Also, Lent et al. (1996) did another model where personal mastery, emotional arousal and verbal persuasion formed one factor, and vicarious learning only formed a separate factor. In this study, we also present a 3-factor model where EPM, EVP and EPE covary. Furthermore, we did another 3-factor model where EPM, EVP, and EVL formed one factor. Since several studies that have developed scales using learning experiences did not separate emotional arousal into positive and negative components, we wanted to see if combining the EPE and ENE to form one factor would negatively affect the scale. Finally, we combined the whole subscale to determine whether the scale is unidimensional.

Also, research (e.g., Dempsey \& Jennings, 2014) has found gender to influence many entrepreneurial outcomes. Therefore, we tried to see if the scale is invariant across genders.

\subsubsection{Convergent and discriminant validity}

Convergent validity is the extent to which measures designed for a particular construct are related. Contrastingly, discriminant validity is the extent to which scales designed to measure opposing constructs are uncorrelated. Authors have investigated these validities from different perspectives. Some (e.g., Miller, Ewest, \& Neubert, 2019) have correlated related constructs to determine convergent validity and connected unrelated constructs to assess discriminant validity. Others (e.g. Wang, Tseng, Wang, \& Chu, 2020) have used the extent to which items designed to measure the same construct are correlated, as convergent validity, and the degree to which items to measure different constructs are uncorrelated as discriminant validity. Still, scholars (e.g., Lanero et al., 2016; Pattnaik, 2019; Pei-Boon, Jaafar, Chin-Siang, \& Nee-Nee, 2020, pp. 1-12) use average variance extracted (AVE), which is the amount of variance a scale captures from its indicators, relative to the amount of measurement errors (Farrell, 2010). Values greater than 0.5 for each measured construct are regarded as meeting convergent validity requirements (Fornell \& Larcker, 1981). In comparison, discriminant validity is determined when the square root of the measured scales is greater than its correlation with other scales (Netemeyer, Bearden, \& Sharma, 2003). In this phase of the study, we used AVE.

\subsubsection{Composite reliability}

Finally, for reliability, we computed both Cronbach's alpha and composite reliability. Both are suitable methods for determining the reliability of a scale. However, there are researchers (e.g., Bacon, Sauer, \& Young, 1995; Peterson \& Kim, 2013) that argue that the latter is better than the former. Values above 0.70 are considered reasonable for Cronbach alpha and composite reliability (Nunnally, 1978; Nunnally \& Bernstein, 1994).

\subsubsection{Sampling technique}

For phase 3, we purposively collected data from three tertiary institutions in Ekiti state - a state in southwestern Nigeria. Each tertiary institution was chosen to represent a different SES. Adebusuyi and Adebusuyi (2020) discussed how different tertiary institutions could be used as a proxy to measure students' SES in Nigeria. Guided by their example, we collected data from Afe Babalola University, Ado-Ekiti (a private university) - as a proxy for high SES students. Also, we collected data from Ikere College of Education, as a proxy for low SES students. Finally, we collected data from Federal University, Oye-Ekiti - as a proxy for a mix of high and low SES students. All of these were done to ensure the scale's generalizability across different social classes.

\subsubsection{Participants}

The study participants were 376 undergraduate students which 137 (36.4\%) were males, 238 (63.3\%) were females, and one person $(0.3 \%)$ did not indicate sex. Their ages ranged from 16 to $30\left(M_{\text {age }}=21.75 ; S D=2.84\right)$. For religion: $324(86.2 \%)$ were Christians, 45 were Muslims (12\%), 5 (1.3\%) traditional religion and $2(0.5 \%)$ did not indicate religion. One hundred and two (27.1\%) samples were collected from Afe Babalola University, Ado-Ekiti, 205 (54.5\%) samples were collected from Federal University, OyeEkiti, and 69 (18.4\%) samples were collected from Ikere College of Education. The respondents were from faculties and 
departments of the tertiary institutions used. Out of the 376 respondents, 51 (13.56\%) had 1 to 6 item responses missing.

\subsubsection{Measures}

ESE. The ESE scale used for this study was developed by Moberg (2013). This scale was because it was designed to measure the ESE of people with little or no entrepreneurial experience. It is a 20 item scale with five sub-dimensions. The whole scale was collapsed in this study to produce one general ESE measure. Sample item includes: "Identify ways to combine resources in new ways to achieve". For reliability, the scale ranged from 0.67 to 0.85 for the five subscales. The collapsed general ESE scale has a Cronbach's alpha of .88. For validity, Moberg did an EFA and CFA. The CFA fit statistics showed: Comparative fit index (CFI) > 0.90, Standardized Root Mean Square Residual (SRMR) $<0.08$ and the Root Mean Square Error of Approximation (RMSEA) ranged from 0.06 to 0.07.

EOE. The EOE scale we used was developed by Lanero et al. (2016). The scale has two factors of intrinsic and extrinsic EOE. The reliability coefficient for each subscale was 0.92 . Also, the combined scale used in this study has a 0.92 reliability coefficient. A convergent validity using the average variance extracted (AVE) value for each subscale were 0.64 and 0.70 . For this study, however, the two were also collapsed into one single measure of EOE. The combined EOE scale is a 14-item scale measured on a Likert scale from (1) strongly disagree to (7) strongly agree. Sample item includes: "As an entrepreneur, I would obtain work autonomy and independence". The reliability coefficient for the collapsed scale was 0.85 .

Neuroticism. This was measured using the Big Five Inventory (BFI) developed by John and Srivastava (1999). A 44-item scale measured on a 5-point Likert-type scale ranging from (1) strongly disagree to (5) strongly agree. However, we used the neuroticism subscale, comprising of 8 items. Sample item includes: "I see myself as someone who gets nervous easily." It has been used in several empirical studies and has been reported to have a Cronbach's alpha of .87.

\section{Results}

\subsection{Factor analysis of the ELE items}

The data of the 49 items developed to measure EPM, EVL, EVP, EPE, and ENE were subjected to maximum likelihood (ML) extraction method and promax rotation in EFA. We used ML because, according to Worthington and Whittaker (2006), it is better for scale development and is the estimation method of CFA. Also, we followed the precedence of Usher and Pajares (2009), who used ML to extract their EFA sources of mathematics self-efficacy. Items that fall below .40 in the communalities, its primary factor in the pattern matrix, and cross-loadings $<0.15$ on non-primary factors were deleted as recommended by Howard (2015). This process removed 25 out of the original 49 items, and all of the negatively worded items were deleted. The factor that suffered the most in this process of elimination was EPM. Most of the items developed to measure it were removed to retain only two items.

The retained 24 items have a Kaiser-Meyer-Olkin measure of sampling adequacy (KMO) of 0.872 (which is meritorious according to Hutcheson \& Sofroniou, 1999). Also, the values for the individual KMO ranged from 0.788 to 0.933 , which is greater than the acceptable limit of 0.5, according to Field (2018). Based on Kaiser's criterion of 1 and the scree plot, the EFA produced five

Table 1

Items and factor loadings for entrepreneurial learning experiences.

\begin{tabular}{|c|c|c|c|c|c|}
\hline & EPE & ENE & EVP & EVL & EPM \\
\hline Attentive & .773 & & & & \\
\hline Interested & .767 & & & & \\
\hline Inspired & .722 & & & & \\
\hline Strong & .674 & & & & \\
\hline Determined & .667 & & & & \\
\hline Excited & .625 & & & & \\
\hline Irritable & & .828 & & & \\
\hline Jittery & & .765 & & & \\
\hline Hostile & & .706 & & & \\
\hline Distressed & & .700 & & & \\
\hline Ashamed & & .667 & & & \\
\hline People close to me have verbally declared their faith in my abilities to succeed as an entrepreneur & & & .911 & & \\
\hline My parents have encouraged me to develop my entrepreneurial skills & & & .718 & & \\
\hline People have told me that I am a born entrepreneur & & & .660 & & \\
\hline I have been praised for my entrepreneurial abilities in the past & & & .578 & & \\
\hline People close to me have let me know that I am good at entrepreneurship & & & .461 & & \\
\hline I have role models who are good entrepreneurs & & & & .687 & \\
\hline I have role models who have explained to me how to be a successful entrepreneur & & & & .674 & \\
\hline I have family relations that I admire making good money as entrepreneurs & & & & .654 & \\
\hline I have seen friends doing well as entrepreneurs & & & & .612 & \\
\hline When I read about successful entrepreneurs, I see myself becoming one & & & & .459 & \\
\hline I have followed very closely (on TV or internet) entrepreneurs that I admire a lot & & & & .441 & \\
\hline I have been successful at selling things in the past & & & & & .813 \\
\hline I have been good at trading/exchange of things in the past & & & & & .791 \\
\hline Eigenvalues & 6.52 & 3.26 & 2.16 & 2.16 & 1.16 \\
\hline$\%$ of Variance & 27.14 & 13.56 & 9.01 & 9.01 & 4.84 \\
\hline
\end{tabular}


theory-consistent factors, with total variance, explained at $51.22 \%$. Although there are no specific criteria for the level of total variance explained, Pett, Lackey, and Sullivan (2003) recommended a range of 50-60 per cent for EFA in social sciences. Therefore, our variance explained is acceptable as it falls within this range. We present the eigenvalues, percentage of variance accounted for by each factor and the factor loadings for each item in Table 1.

\subsection{Construct validity}

Correlational analyses, as shown in Table 2, provide evidence for the construct validity of the ELE scales. As indicated in Table 2, EPM was positively associated with ESE $(r=0.45)$ and EOE $(r=0.34)$, but, although not significant, was negatively related to neuroticism $(r=-0.03)$. Similarly, EVL was positively related to ESE $(r=0.49)$ and EOE $(r=0.50)$, but negatively related to neuroticism $(r=-0.05)$. Also, EVP positively related to ESE $(r=0.52)$ and EOE $(r=0.39)$. EPE also positively related to ESE $(r=0.66)$ and EOE $(r=0.52)$, whereas, it negatively related to neuroticism $(r=-0.11)$. Finally, ENE was negatively related to ESE $(r=-0.11)$ and $\mathrm{EOE}(r=-0.24)$, but positively related to neuroticism $(r=0.26)$.

\subsection{Confirmatory factor analysis}

We used Analysis of Moment Structure (AMOS) version 23 for the CFA. As recommended by Hair, Black, Babin, and Anderson (2013) and Bentler and Bonett (1980), the threshold for a good model fitness includes the following: RMSEA $\leqslant 0.08$, SRMR $\leqslant 0.10$, and $\mathrm{CFI} \geqslant 0.9$.

The result of the CFA, using the 5-factor model we found in phase 2 of this study yielded a well-fitting model $\left(\chi^{2}{ }_{(242)}=519.677\right.$, $p$ $<.001, \mathrm{CFI}=0.946$, RMSEA $=0.055$ and SRMR $=0.0514$ ) as presented in the first row of Table 3 (model 1 ). The goodness of fit of the alternative models are also presented in Table 3 (models 2 to 6).

To determine the difference between fit indices of the models, the Akaike information criterion (AIC) was used, with lower values indicating better fit. Other researchers (e.g., Miller et al., 2019; Gunawan, Creed, \& Glendon, 2018) have also used it to compare models. Comparing the 5-factor model with the alternative models presented in Table 3, it is clear that the 5-factor model is the best. The one that came close is model 2, and the worst is model 6. Summarily, the CFA in phase 3 confirmed the EFA in phase 2. The result of the 5 -factor CFA is illustrated in Fig. 1. As shown in Fig. 1, all the standardized factor loading ranged from 0.64 to 0.86 , and significant at $p<.001$.

Furthermore, we checked for the invariance of the scale across genders. According to Byrne (2016), two analyses must be carried out. The first is the configural model, where the groups will be nested within one hypothesized model. Following this analysis is the constrained model, where the nested models are forced to be equal. This analysis was done for both the factor loadings of the CFA and their covariances, leaving out their error variances, as recommended by Byrne (2016). The test of invariance is determined by the non-significant difference between the configural $\chi^{2}$ and the constrained model.

The gender configural model yielded the following: $\chi^{2}{ }_{(484)}=874.122, \mathrm{CFI}=0.926$, RMSEA $=0.046$ and SRMR $=0.0665$. Whereas, the constrained model for the factor loadings produced the following: $\chi^{2}{ }_{(242)}=894.605, \mathrm{CFI}=0.926, \mathrm{RMSEA}=0.046$ and SRMR $=$ 0.0689 . The chi-square difference test between the configural and the constrained model $\Delta \chi_{(19)}^{2}=20.483, \mathrm{p}=.366$, implying that the model is the same across gender for the factor loadings. The constrained model for the covariances: $\chi^{2}{ }_{(518)}=916.827, \mathrm{CFI}=0.924$, RMSEA $=0.045$ and SRMR $=0.0794$. The chi-square difference between the configural and the constrained covariances $\Delta \chi^{2}(15)=$ $22.22, \mathrm{p}=.102$.

\subsection{Convergent and discriminant validity and reliability}

As shown in Table 4, the AVE of the ELE subscales ranged from 0.529 to 0.709 - above the minimum threshold of 0.50 . Therefore, the convergent validity requirement is satisfied. Also, the square roots of the AVE (the values in parentheses on the diagonal) are larger than the correlations on the off diagonals, implying discriminant validity requirements are also satisfied.

Finally, Table 4 shows both the Cronbach's alpha and composite reliability values. Both exceeded the minimum standard of 0.70 . Although composite reliability is better, the difference between them is negligible, supporting the conclusion of Peterson and Kim

Table 2

Correlations, means, standard deviations, and internal consistency estimates.

\begin{tabular}{|c|c|c|c|c|c|c|c|c|c|}
\hline & Mean & SD & EPM & EVL & EVP & EPE & ENE & ESE & EOE \\
\hline EPM & 7.52 & 2.93 & 1 & & & & & & \\
\hline EVL & 26.21 & 7.31 & $.574 * *$ & 1 & & & & & \\
\hline EVP & 19.10 & 6.71 & $.619^{* * *}$ & $.597 * *$ & 1 & & & & \\
\hline EPE & 23.16 & 5.43 & $.394^{* *}$ & $.422^{* *}$ & $.428^{* * *}$ & 1 & & & \\
\hline ENE & 10.73 & 5.33 & -.022 & $-.151^{* *}$ & .031 & $-.119 *$ & 1 & & \\
\hline ESE & 85.10 & 18.96 & $.454^{* * *}$ & $.491 \% *$ & $.516^{* * *}$ & $.664 * *$ & $-.107 *$ & 1 & \\
\hline EOE & 65.69 & 15.09 & $.341 * *$ & $.502^{* *}$ & $.372^{* * *}$ & $.519 * *$ & $-.241 * *$ & $.667 * *$ & \\
\hline neuroticism & 23.18 & 4.31 & -.03 & -.049 & -.064 & $-.105^{*}$ & $.258^{* *}$ & -.116 & -.095 \\
\hline
\end{tabular}

Note. ${ }^{*} p<.05, * * p<.01$. 
Table 3

Goodness-of-fit statistics for CFA models.

\begin{tabular}{|c|c|c|c|c|c|c|c|c|}
\hline Model & & $\chi^{2}$ & df & $\chi 2 / \mathrm{df}$ & CFI & SRMR & RMSEA & AIC \\
\hline 1 & Five factors & $519.677^{*}$ & 242 & 2.147 & .946 & .0514 & .055 & 633.677 \\
\hline 2 & Four factors with EPM and EVP as one factor & $653.295^{*}$ & 246 & 2.655 & .921 & .0567 & .066 & 761.295 \\
\hline 3 & Four factors with EPE and ENE as one factor & $1805.662^{*}$ & 246 & 7.340 & .698 & .1975 & .130 & 1913.662 \\
\hline 4 & Three factors, where EPM, EVP, and EPE are one factor & $1475.493^{*}$ & 249 & 5.926 & .762 & .0967 & .115 & 1577.493 \\
\hline 5 & Three factors, where EPM, EVP, and EVL are one factor & $982.946^{*}$ & 249 & 3.948 & .858 & .0699 & .089 & 1084.948 \\
\hline 6 & One factor & $2796.663^{*}$ & 252 & 11.098 & .507 & .1551 & .164 & 2892.663 \\
\hline
\end{tabular}

Note. $\mathrm{N}=376$. AIC $=$ Akaike information criterion; $\mathrm{CFI}=$ Comparative Fit Index; $\mathrm{df}=$ degrees of freedom; RMSEA $=$ root mean square error of approximation. *p $<.001$.

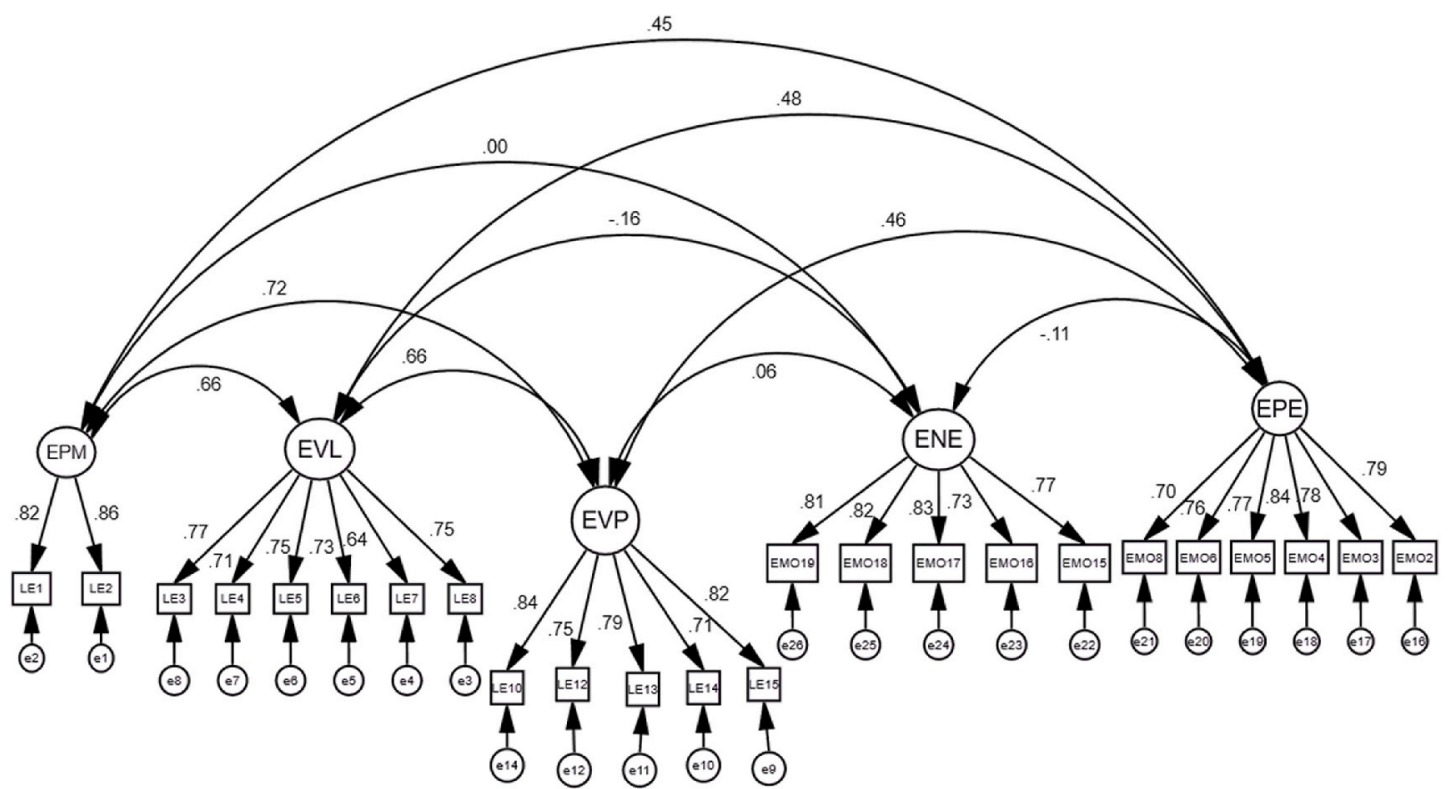

Fig. 1. Measurement model for the 24-item ELE scale.

Table 4

Latent variable correlation matrix, square roots of AVE and composite reliability.

\begin{tabular}{llllllllll}
\hline & $\alpha$ & $\rho c$ & AVE & MSV & EPM & EPE & ENE & EVP & EVL \\
\hline EPM & .829 & 0.830 & 0.709 & 0.524 & $(0.842)$ & & & & \\
EPE & .899 & 0.900 & 0.600 & 0.234 & 0.455 & $(0.774)$ & & $(0.793)$ & $(0.784)$ \\
ENE & .894 & 0.894 & 0.629 & 0.025 & -0.004 & -0.106 & 0.060 & $(0.727)$ \\
EVP & .887 & 0.888 & 0.615 & 0.524 & 0.724 & 0.460 & 0.484 & -0.159 & 0.661 \\
EVL & .869 & 0.870 & 0.529 & 0.440 & 0.663 & 0.484 & $(0.75)$ \\
\hline
\end{tabular}

$\mathrm{AVE}=$ Average Variance Extracted; Square roots of AVE are in parentheses; $\rho \mathrm{c}=$ composite reliability; $\alpha=$ Cronbach's alpha; MSV $=$ maximum shared variance (MSV).

\section{(2013).}

\section{Discussion}

The main goal of this study is to develop an ELE scale that corresponds to the definition and conceptualization of learning experiences by Bandura (1997) and Lent et al. (1994) in an entrepreneurial context. This is necessary to further the application of SCCT in an entrepreneurial context. We did this using established scale development procedures. From the initial 49 items, the result produced a 24-item, theory-consistent 5-factor model. The construct validity showed that each of the ELE (except for ENE) subscales related positively to ESE and EOE scales and negatively related to neuroticism (although not significantly) as posited by the SCCT model. On the reverse side, only ENE positively related to neuroticism.

Several authors (e.g., Netemeyer et al., 2003; Worthington \& Whittaker, 2006) have argued that CFA should be done after the EFA. We followed the same process in this study. We found that CFA confirmed the theoretical factor structure of the ELE subscales found in 
EFA in a different sample. It also serves as a form of convergent validity, as none of the items had less than 0.60 on their primary factor. We also observed that there was no error covariance to suggest any theory modification during the CFA analysis. Besides, we found that the ELE scale was invariant across gender, both at the configural and more stringent level of analysis (i.e. equality constraint model). This finding is crucial because gender differences have been found to influence many entrepreneurial outcomes.

The results of this study on AVE, MSV, and the square roots of AVE all provide evidence of convergent and discriminant validity. The reliability coefficients (either Cronbach's alpha or composite reliability) also exceeded the minimum benchmark for a reliable scale at phases 2 to 3 of the scale development. It is important to note that all of the negatively worded items in the initial item pool were screened out when conducting EFA. According to Usher and Pajares (2009), negatively worded items are problematic when developing sources of self-efficacy scales. This problem manifested itself in the process of screening out items.

One subscale that was difficult to develop items for was EPM. In vocational and career studies, measuring personal mastery is relatively straightforward. Even so, it is not easy because the same level of performance can lead one individual to judge himself as a success and another to judge himself as a failure. The problem is even more amplified in an entrepreneurial context. Definition of success in entrepreneurship can either be economical (e.g., profit maximization) or psychological (e.g., derivation of personal fulfilment) or both (Staniewski \& Awruk, 2019). A typical student has limited entrepreneurial experiences; therefore, judging his/her efforts as either successful or failure will be difficult.

Furthermore, notice that EPM has the highest correlation with EVP $(r=.62)$. According to Lent et al. (2017), in a situation where objective performance standards are lacking, information about EPM and EVP will covary because people will rely on the assessment of significant others. Similarly, in an entrepreneurial context, undergraduates do not have objective performance standards for their entrepreneurial efforts. Therefore, their opinions of their EPM tend to come from the views of others (i.e., EVP). Furthermore, note that EPM did not have the highest correlation with ESE and EOE, contrary to the theoretical proposition of SCCT. In support of this result, Bike (2013) also found that personal mastery had a low influence on self-efficacy.

\section{Research implications and limitations of the study}

This paper proposes a new instrument based on the SCCT. ESE has been empirically found to influence many entrepreneurial outcomes (Newman et al., 2019). Nevertheless, research investigating its outcomes are far more than those of its antecedents (Javadian, Opie, \& Parise, 2018). The first crucial implication of this study is that it offers an alternative theory to investigate the antecedents of ESE through a robust and integrated framework of the SCCT. Second, entrepreneurial researchers can now combine the distal and proximal parts of SCCT in an entrepreneurial context, thereby deepening our understanding of entrepreneurial intention, behaviour, and success.

This research also has implications for entrepreneurial pedagogy in terms of bespoke curriculum design for various entrepreneurial outcomes and various stages in the entrepreneurial process and experience. For example, entrepreneurial education and training aimed at potential, aspiring and early-stage entrepreneurs should have certain distinct features and components from those aimed at "continuing" entrepreneurs. In the same vein, the paper has implications for entrepreneurship and education policy, for example, in Nigeria and many African countries, where national governments have launched policies of compulsory entrepreneurship education in the higher education sector (Kolade, 2018). Universities play a critical role in supplying high-quality entrepreneurs in developing countries (Olofinyehun, Adelowo, \& Egbetokun, 2018). However, educators and policymakers need to account better for other forms of entrepreneurial learning outside the traditional classroom, whether within or outside the university environment. These include opportunities for entrepreneurial learning, mentorship and co-creation in venture incubation and acceleration spaces spearheaded by a growing number of tech hubs and DIY labs across the African continent (Atiase, Kolade, \& Liedong, 2020; Kolade, Atiase, Murithi, \& Mwila, 2021). They also include apprenticeships and industrial training programmes, which can be re-designed to reflect new realities and prepare participants for new entrepreneurial opportunities in the 21 st-century knowledge economy. Social cognitive career theory provides a framework to better understand and capture these additional elements of entrepreneurial learning. This can indirectly inform better evaluation processes for entrepreneurship education programmes.

Finally, most research on SCCT has been carried out in Europe and America; this research showed the model's applicability in an international sample. Brown and Lent (2016) already asked for the application of the theory to a new context and understudied culture. This research fills the gap by applying the model to a sample of undergraduate students in Nigeria, Africa's most populous country and biggest economy.

There are some limitations and future research potentials arising from this study. First, while the two items measuring EPM meet the minimum number of items, according to Worthington and Whittaker (2006), we recommend that future research add more to the items. Second, there is a need to apply this scale in a different population and culture other than the Nigerian context. Finally, related entrepreneurial scales could be included in a future study to see whether the scale has a better predictive ability.

\section{Authorship}

Adeola Samuel Adebusuyi (lead author): He is responsible for the conception, design of the study, data analysis and writing of the original draft.

Olubusayo Foluso Adebusuyi: She is responsible for the data collection, editing and revising of the draft

Oluwaseun Kolade: Along with editing the manuscript for better clarity and coherence, his contributions helped shaped the theory section, discussion of findings and implications. 


\section{Appendix A. Supplementary data}

Supplementary data to this article can be found online at https://doi.org/10.1016/j.ijme.2021.100572.

\section{References}

Abbasianchavari, A., \& Moritz. (2021). The impact of role models on entrepreneurial intentions and behavior: A review of the literature. Management Review Quarterly, 71, 1-40. https://doi.org/10.1007/s11301-019-00179-0

Adebusuyi, A. S., \& Adebusuyi, O. F. (2020). The influence of social class on entrepreneurial self-efficacy and outcome expectations. Small Enterprise Research, 259-274. https://doi.org/10.1080/13215906.2020.1844044

Adebusuyi, A. S., Kolawole, S. O., Abu, S. H., Adebusuyi, O. F., \& Ajulo, A. A. (2021). Predicting entrepreneurial and professional career mindsets in young Nigerian adults. Journal of Entrepreneurship in Emerging Economies. https://doi.org/10.1108/JEEE-02-2021-0072

Ajzen, I. (1991). The theory of planned behavior. Organizational Behavior and Human Decision Processes, 50(2), 179-211. https://doi.org/10.1016/0749-5978(91) 90020-T

Atiase, V. Y., Kolade, O., \& Liedong, T. A. (2020). The emergence and strategy of tech hubs in Africa: Implications for knowledge production and value creation. Technological Forecasting and Social Change, 161, 120307. https://doi.org/10.1016/j.techfore.2020.120307

Bacon, D. R., Sauer, P. L., \& Young, M. (1995). Composite reliability in structural equations modeling. Educational and Psychological Measurement, 55, 394-406. https://doi.org/10.1177/0013164495055003003

Bandura, A. (1986). Social foundations of thoughts and actions: A social cognitive theory. Prentice-Hall, Inc.

Bandura, A. (1997). Self-efficacy: The exercise of control. New York, NY: W.H. Freeman.

BarNir, A., Watson, W. E., \& Hutchins, H. M. (2011). Mediation and moderated mediation in the relationship among role models, self-efficacy, entrepreneurial career intention, and gender. Journal of Applied Social Psychology, 41(2), 270-297.

Bentler, P. M., \& Bonett, D. G. (1980). Significance tests and goodness of fit in the analysis of covariance structures. Psychological Bulletin, 88(3), 588-606.

Bike, D. H. (2013). Career decision learni1ng experiences: Development and validation of a scale (unpublished doctoral dissertation). Columbia, MO: University of Missouri. Retrieved from https://mospace.umsystem.edu/xmlui/bitstream/handle/10355/39754/research.pdf?sequence=2.

Brown, S. D., \& Lent, R. W. (2016). Social cognitive career theory in a diverse world: Closing thoughts. Journal of Career Assessment, 25, 173-180. https://doi.org/ $10.1177 / 1069072716660061$

Byrne, B. M. (2016). Structural equation modeling with AMOS (3rd ed.). New York: Routledge.

Cardon, M. S., Foo, M. D., Shepherd, D., \& Wiklund, J. (2012). Exploring the heart: Entrepreneurial emotion is a hot topic. Entrepreneurship: Theory and Practice, 36(1), $1-10$.

Cardon, M. S., Gregoire, D. A., Stevens, C. E., \& Patel, P. C. (2013). Measuring entrepreneurial passion: Conceptual foundations and scale validation. Journal of Business Venturing, 28(3), 373-396.

Carsrud, A., Brännback, M., Elfving, J., \& Brandt, K. (2009). Motivations: The entrepreneurial mind and behavior. In L. A, Carsrud, \& M. Brännback (Eds.), Understanding the entrepreneurial mind, international studies in entrepreneurship (pp. 141-165). New York: Springer.

Dempsey, D., \& Jennings, J. (2014). Gender and entrepreneurial self-efficacy: A learning perspective. International Journal of Gender and Entrepreneurship, 6(1), 28-49. DeVellis, R. F. (2017). Scale development: Theory and applications (4 ${ }^{\text {th }}$ ed.). Newbury Park, CA: Sage.

Duffy, R. D., Blustein, D. L., Diemer, M. A., \& Autin, K. L. (2016). The psychology of working theory. Journal of Counseling Psychology, 63(2), 127-148.

Erikson, T. (1999). A study of entrepreneurial career choices among MBAs - the extended Bird model. Journal of Enterprising Culture, 7(1), 1-17.

Farashah, A. D. (2015). The effects of demographic, cognitive and institutional factors on development of entrepreneurial intention: Toward a socio-cognitive model of entrepreneurial career. Journal of International Entrepreneurship, 13(4), 452-476.

Farrell, A. M. (2010). Insufficient discriminant validity: A comment on Bove, Pervan, Beatty, and Shiu (2009). Journal of Business Research, 63(3), 324-327.

Field, A. (2018). Discovering statistics using IBM SPSS statistics (5th ed.). London: Sage.

Fodor, O. C., \& Pintea, S. (2017). The "emotional side" of entrepreneurship: A meta-analysis of the relation between positive and negative affect and entrepreneurial performance. Frontiers in Psychology, 8.

Fornell, C., \& Larcker, D. F. (1981). Evaluating structural equation models with unobservable variables and measurement error. Journal of Marketing Research, 18(1), $39-50$.

Gunawan, W., Creed, A. P., \& Glendon, A. I. (2018). Development and initial validation of a perceived future employability scale for young adults. Journal of Career Assessment, 1-18. https://doi.org/10.1177/1069072718788645

Hair, J. F., Jr., Black, W. C., Babin, B. J., \& Anderson, R. E. (2013). Multivariate data analysis: A global perspective (7th ed.). Englewood Cliffs, NJ: Prentice Hall.

Howard, M. C. (2015). A review of exploratory factor analysis decisions and overview of current practices: What we are doing and how can we improve? International Journal of Human-Computer Interaction, 32(1), 51-62.

Hutcheson, G., \& Sofroniou, N. (1999). The multivariate social scientist. London: Sage.

Iacobucci, D. (2010). Structural equation modeling: Fit indices, sample size, and advanced topics. Journal of Consumer Psychology, 20, 90-98. https://doi.org/ $10.1016 /$ j.jcps.2009.09.003

Javadian, G., Opie, T. R., \& Parise, S. (2018). The influence of emotional carrying capacity and network ethnic diversity on entrepreneurial self-efficacy. The case of black and white entrepreneurs. New England Journal of Entrepreneurship, 21(2), 101-122. https://doi.org/10.1108/NEJE-08-2018-0016

John, O. P., \& Srivastava, S. (1999). The big-five trait taxonomy: History, measurement, and theoretical perspectives. In L. Pervin, \& O. P. John (Eds.), Handbook of personality: Theory and research (2nd ed., pp. 102-138). New York: Guilford.

Kolade, O. (2018). Venturing under fire: Entrepreneurship education, venture creation, and poverty reduction in conflict-ridden Maiduguri, Nigeria. Education + Training, 60, 749-766.

Kolade, O., Atiase, V., Murithi, W., \& Mwila, N. (2021). The business models of tech hubs in Africa: Implications for viability and sustainability. Technology Analysis \& Strategic Management, 1-13. https://doi.org/10.1080/09537325.2021.1947492, 0(0).

Lanero, A., Vázquez, J. L., \& Aza, C. L. (2016). Social cognitive determinants of entrepreneurial career choice in university students. International Small Business Journal: Researching Entrepreneurship, 34(8), 1053-1075.

Lee, C., Hallak, R., \& Sardeshmukh, S. R. (2016). Innovation, entrepreneurship, and restaurant performance: A higher-order structural model. Tourism Management, $53,215-228$

Lent, R. W., \& Brown, S. D. (2019). Social cognitive career theory at 25: Empirical status of the interest, choice, and performance models. Journal of Vocational Behavior, 115, 103316. https://doi.org/10.1016/j.jvb.2019.06.004

Lent, R. W., Brown, S. D., \& Hackett, G. (1994). Toward a unifying social cognitive theory of career and academic interest, choice, and performance. Journal of Vocational Behavior, 45(1), 79-122.

Lent, R. W., Ireland, G. W., Penn, L. T., Morris, T. R., \& Sappington, R. (2017). Sources of self-efficacy and outcome expectations for career exploration and decisionmaking: A test of the social cognitive model of career self-management. Journal of Vocational Behavior, 99, $107-117$.

Lent, R. W., Lopez, F. G., Brown, S. D., \& Gore, P. A. (1996). Latent structure of the sources of Mathematics self-efficacy. Journal of Vocational Behavior, 49, $292-308$.

Liguori, E. W., Bendickson, J. S., \& McDowell, W. C. (2018). Revisiting entrepreneurial intentions: A social cognitive career theory approach. The International Entrepreneurship and Management Journal, 14(1), 67-78. https://doi.org/10.1007/s11365-017-0462-7 
Liguori, E., Winkler, C., Vanevenhoven, J., Winkel, D., \& James, M. (2019). Entrepreneurship as a career choice: Intentions, attitudes, and outcome expectations. Journal of Small Business and Entrepreneurship, 1-21. https://doi.org/10.1080/08276331.2019.1600857

Liñán, F., \& Chen, Y. (2009). Development and cross-cultural application of a specific instrument to measure entrepreneurial intentions. Entrepreneurship: Theory and Practice, 33(3), 593-617.

Liñán, F., \& Fayolle, A. (2015). A systematic literature review on entrepreneurial intentions: Citation, thematic analyses, and research agenda. The International Entrepreneurship and Management Journal, 11(4), 907-933. https://doi.org/10.1007/s11365-015-0356-5

Mauer, R., Eckerle, P., \& Brettel, M. (2013). Adding missing parts to the intention puzzle in entrepreneurship education: Entrepreneurial self-efficacy, its antecedents and their direct and mediated effects. In R. F Welter, E. Blackburn, Ljunggren, \& B. W. Amo (Eds.), Entrepreneurial business and society frontiers in European entrepreneurship research (pp. 127-148). UK: Edward Elgar Publishing Limited.

Meoli, Fini, Sobrero, \& Wiklund. (2020). How entrepreneurial intentions influence entrepreneurial career choices: The moderating influence of social context. Journal of Business Venturing, 35(3). https://doi.org/10.1016/j.jbusvent.2019.105982

Miller, D. W., Ewest, T., \& Neubert, M. J. (2019). Development of the integration profile (TIP) faith and work integration scale. Journal of Business Ethics, 159, 455-544. https://doi.org/10.1007/s10551-017-3773-2

Moberg, S. K. (2013). An entrepreneurial self-efficacy scale with a neutral wording. In A. Fayolle, P. Kyrö, T. Mets, \& U. Venesaar (Eds.), Conceptual richness and methodological diversity in entrepreneurship research (pp. 67-94). Cheltenham: Edward Elgar.

Neneh, B. (2019). From entrepreneurial intentions to behavior: The role of anticipated regret and proactive personality. Journal of Vocational Behavior, 112, 311-324.

Netemeyer, R. G., Bearden, W. O., \& Sharma, S. (2003). Scaling procedures: Issues and application. London: Sage.

Newman, A., Obschonka, M., Schwarz, S., Cohen, M., \& Nielsen, I. (2019). Entrepreneurial self-efficacy: A systematic review of the literature on its theoretical foundations, measurement, antecedents, and outcomes, and an agenda for future research. Journal of Vocational Behavior, 110, $403-419$.

Nowiński, W., \& Haddoud, M. Y. (2019). The role of inspiring role models in enhancing entrepreneurial intention. Journal of Business Research, 96, 183-193.

Nunnally, J. C. (1978). Psychometric theory. New York: McGraw-Hill.

Nunnally, J. C., \& Bernstein, I. H. (1994). Psychometric theory (3rd ed.). New York: McGraw-Hill.

Obschonka, M., Silbereisen, R. K., Schmitt-Rodermund, E., \& Stuetzer, M. (2011). Nascent entrepreneurship and the developing individual: Early entrepreneurial competence in adolescence and venture creation success during the career. Journal of Vocational Behavior, 79(1), $121-133$.

Olofinyehun, A. O., Adelowo, C. M., \& Egbetokun, A. A. (2018). The supply of high-quality entrepreneurs in developing countries: Evidence from Nigeria. Science and Public Policy, 45(2), 269-282. https://doi.org/10.1093/scipol/scx065

Pattnaik, S. (2019). Working with second-order construct in measurement model: An illustration using empirical data. In R. N. Subudhi, \& S. Mishra (Eds.), Methodological issues in management research: Advances, challenges, and the way ahead (pp. 249-259). UK: Edward Elgar Publishing Limited.

Pei-Boon, O., Jaafar, W. M. W., Chin-Siang, A., \& Nee-Nee, C. (2020). Psychometric properties of the sources of counseling self efficacy in a sample of Malaysian secondary school counselors. Sage Open. https://doi.org/10.1177/2158244020902076

Pérez-López, M. C., González-López, M. J., \& Rodríguez-Ariza, L. (2019). Applying the social cognitive model of career self-management to the entrepreneurial career decision: The role of exploratory and coping adaptive behaviours. Journal of Vocational Behavior, 112(March), 255-269. https://doi.org/10.1016/j. jvb.2019.03.005

Peterson, R. A., \& Kim, Y. (2013). On the relationship between coefficient alpha and composite reliability. Journal of Applied Psychology, 98(1), 194-198. https://doi. org/10.1037/a0030767

Pett, M. A., Lackey, N. R., \& Sullivan, J. J. (2003). Making sense of factor analysis: The use of factor analysis for instrument development in health care research. California: Sage publication.

Pham, D., Jones, P., Dobson, S., Liñán, F., \& Viala, C. (2021). Entrepreneurial implementation intention as a tool to moderate the stability of entrepreneurial goal intention: A sensemaking approach. Journal of Business Research, 123, 97-105.

Schaub, M., \& Tokar, D. M. (2005). The role of personality and learning experiences in social cognitive career theory. Journal of Vocational Behavior, 66(2), 304-325. https://doi.org/10.1016/j.jvb.2004.09.005

Singer, J. D., \& Willett, J. B. (2003). Applied longitudinal data analysis: Modeling change and event occurrence. New York, NY: Oxford University Press.

Staniewski, M. W., \& Awruk, K. (2019). Entrepreneurial success and achievement motivation - a preliminary report on a validation study of the questionnaire of entrepreneurial success. Journal of Business Research, 101, 433-440.

Sun, H., Ni, W., Teh, P., \& Lo, C. (2020). The systematic impact of personal characteristics on entrepreneurial intentions of engineering students. Frontiers in Psychology, 11. https://doi.org/10.3389/fpsyg.2020.01072

Tabachnick, B. G., \& Fidell, L. S. (2013). Using multivariate statistics (6th ed.). Boston, MA: Pearson Education.

Tokar, D. M., Thompson, M. N., Plaufcan, M. R., \& Williams, C. M. (2007). Precursors of learning experiences in social cognitive career theory. Journal of Vocational Behavior, 71(3), 319-339. https://doi.org/10.1016/j.jvb.2007.08.002

Usher, E. L., \& Pajares, F. (2009). Sources of self-efficacy in mathematics: A validation study. Contemporary Educational Psychology, 34, 89-101.

Vanevenhoven, J., \& Liguori, E. (2013). The impact of entrepreneurship education: Introducing the entrepreneurship education project. Journal of Small Business Management, 51(3), 315-328. Psychologist, 34(5), 719-751.

Wang, Y., Tseng, T. H., Wang, Y., \& Chu, C. (2020). Development and validation of an internet entrepreneurial self-efficacy scale. Internet Research, 30(2), 653-675. https://doi.org/10.1108/INTR-07-2018-0294

Watson, D., Clark, L. A., \& Tellegen, A. (1988). Development and validation of brief measures of positive and negative affect: The PANAS scales. Journal of Personality and Social Psychology, 54(6), 1063-1070.

Weston, R., \& Gore, P. A. (2006). A brief guide to structural equation modeling. The Counseling Psychologist, 34(5), 719-751.

Worthington, R. L., \& Whittaker, T. A. (2006). Scale development research. The Counseling Psychologist, 34(6), 806-838.

Zhao, H., Seibert, S. E., \& Hills, G. E. (2005). The mediating role of self-efficacy in the development of entrepreneurial intentions. Journal of Applied Psychology, 90(6), 1265-1272. 